Virginia Commonwealth University VCU Scholars Compass

2015

\title{
Children's experiences of companion animal maltreatment in households characterized by intimate partner violence
}

Shelby Elaine McDonald

Virginia Commonwealth University

Elizabeth A. Collins

Colorado Coalition Against Domestic Violence

Nicole Nicotera

University of Denver

See next page for additional authors

Follow this and additional works at: https://scholarscompass.vcu.edu/socialwork_pubs

Part of the Social Work Commons

(C) 2015 Elsevier Ltd. All rights reserved.

\section{Downloaded from}

https://scholarscompass.vcu.edu/socialwork_pubs/17

This Article is brought to you for free and open access by the School of Social Work at VCU Scholars Compass. It has been accepted for inclusion in Social Work Publications by an authorized administrator of VCU Scholars Compass. For more information, please contact libcompass@vcu.edu. 
Authors

Shelby Elaine McDonald, Elizabeth A. Collins, Nicole Nicotera, Tina O. Hageman, Frank R. Ascione, James Herbert Williams, and Sandra A. Graham-Bermann 


\section{Abstract}

Cruelty toward companion animals is a well-documented, coercive tactic used by abusive partners to intimidate and control their intimate partners. Experiences of co-occurring violence are common for children living in families with intimate partner violence (IPV) and surveys show that more than half are also exposed to abuse of their pets. Given children's relationships with their pets, witnessing such abuse may be traumatic for them. Yet little is known about the prevalence and significance of this issue for children. The present study examines the experiences of children in families with co-occurring pet abuse and IPV. Using qualitative methods, 58 children ages 7-12 who were exposed to IPV were asked to describe their experiences of threats to and harm of their companion animals. Following the interviews, template analysis was employed to systematically develop codes and themes. Coding reliability was assessed using Randolph's free-marginal multirater kappa $\left(k_{f r e e}=.90\right)$. Five themes emerged from the qualitative data, the most common being children's exposure to pet abuse as a power and control tactic against their mother in the context of IPV. Other themes were animal maltreatment to discipline or punish the pet, animal cruelty by a sibling, children intervening to prevent pet abuse, and children intervening to protect the pet during a violent episode. Results indicate that children's experiences of pet abuse are multifaceted, potentially traumatic, and may involve multiple family members with diverse motives.

sem9883@gmail.com (Corresponding Author).

Publisher's Disclaimer: This is a PDF file of an unedited manuscript that has been accepted for publication. As a service to our customers we are providing this early version of the manuscript. The manuscript will undergo copyediting, typesetting, and review of the resulting proof before it is published in its final citable form. Please note that during the production process errors may be discovered which could affect the content, and all legal disclaimers that apply to the journal pertain. 


\section{Keywords}

Domestic violence; Childhood trauma; Pet Abuse

\section{Introduction}

The majority of children in the United States experience myriad forms of direct and indirect violence exposure in their daily lives (Hamby, Finkelhor, Turner, \& Ormrod, 2011; McDonald, Jouriles, Ramisetty-Mikler, Casetano, \& Green, 2006). Estimates of children's exposure to intimate partner violence (IPV) range extensively (Carlson, 2000; Edleson et al., 2007). Among recent nationally representative surveys, Hamby et al. (2011) report that approximately $17.9 \%$ of children age 17 years or younger are exposed to physical IPV during their lifetime. Estimates generated from large-scale studies point to the widespread prevalence of the issue in society, yet our knowledge of children's exposure to IPV continues to be limited. For example, there is a paucity of empirical knowledge on the types of IPV-related violence to which children are exposed as well as the frequency and proximity of their exposure and involvement in IPV-related events (Edleson et al., 2007; Edleson, Shin, \& Armendariz, 2008). Moreover, the majority of empirical work in this area of study has been quantitative, contributing to a scarcity of research that considers children's subjective experiences of IPV and the context of their exposure (Cunningham \& Baker, 2004; Överlien \& Hydén, 2009).

Children living in homes where IPV is present frequently experience co-occurring maltreatment (Finkelhor, Turner, Hamby, \& Ormond, 2009). They are also more likely to witness violence across multiple contexts such as school and their community than children living in non-violent homes (Finkelhor et al., 2007; Hamby et al., 2011; Lynch \& Cicchetti, 1998; McCabe, Hough, Yeh, Lucchini, \& Hazen, 2005). Among overlapping forms of violence exposure associated with IPV, the link between family violence and animal abuse has garnered increased scholarly attention in the social sciences literature in the past two decades (e.g., Ascione et al., 2007; Volant, Johnson, Gullone, \& Coleman, 2008). Cruelty toward pets is a well-documented, coercive tactic used by abusive partners to intimidate and control their victim (Faver \& Strand, 2007). Despite scholarly recognition of the importance of assessing overlapping and interconnected forms of violence exposure among children (Margolin et al., 2009; Finkelhor et al., 2007), there has been a dearth of empirical attention to the prevalence and significance of children's concomitant exposure to abuse of animals in IPV-affected homes.

The limited body of published research in this area suggests that between one-half and threefourths of abused women with companion animals report that their pets have been threatened and/or harmed by an intimate partner (Ascione, 1998; Ascione et al., 2007; Faver \& Strand, 2003; Faver \& Strand, 2007; Flynn, 2000a; Flynn, 2000b; Flynn, 2009; Volant et al., 2008). Concurrently, research has indicated that children from homes characterized by IPV witness significantly more cruelty toward animals than children from nonviolent families (Ascione et al., 2007; Volant et al., 2008). Ascione et al. (2007) noted that $61.5 \%$ of women with children who were residing at a domestic violence shelter reported that their 
children had heard or seen pet abuse in contrast to only $2.9 \%$ of women reporting no IPV victimization. Moreover, $67 \%$ of children residing in shelter with their mother indicated they had seen or heard one of their pets being hurt; approximately $93 \%$ of these children said they were "very upset" or "sort of upset" as a result of the maltreatment of their companion animal (Ascione et al., 2007).

To date, studies specifically examining children's exposure to the maltreatment of companion animals have relied on dichotomous assessments of animal abuse exposure (exposed vs. non-exposed). Among published research, only Edleson, Shin, and Armendariz (2008) have reported on frequency and proximity of exposure to animal abuse among children of mothers receiving residential or non-residential domestic violence services. In a psychometric evaluation of the Child Exposure to Domestic Violence (CEDV) Scale, the authors reported that $14.3 \%$ of children in their study responded affirmatively to an item asking if their mother's partner had hurt a pet on purpose (Edleson et al., 2008). Qualitative information collected as part of this measure suggested that the majority of children exposed to this form of violence were in close proximity during the time it occurred. Results of this study highlight that children's exposure to harm of companion animals in families experiencing IPV may involve multiple types of exposure (e.g., seeing, hearing) that may be both severe and frequent.

\section{Children's Reactions When Experiencing Intimate Partner Violence}

Recently, scholars such as Överlien and Hydén (2009) have argued for the importance and need for more holistic qualitative investigations of children's experiences and involvement in violent events independent of mothers' experiences of IPV. A small number of studies have attended to children's strategies for coping with and behavioral responses to interparental violence. As a whole, the literature documents a variety of responses such as children removing themselves from the conflict, distracting themselves or caregivers, and/or becoming verbally and/or physically involved in the conflict (Adamson \& Thompson, 1998; Hester \& Radford, 1996; Jaffe, Hurley, \& Wolfe, 1990; Joseph, Govender, \& Bhagwanjee, 2006; Margolin, 1998; McGee, 2000; Överlien \& Hydén, 2009; Solberg, 2004). Edleson et al. (2007) suggest that, "the degree to which a child intervenes in adult domestic violence clearly varies from child to child and is likely related to the impact of exposure" (pg. 964).

Children with strong attachments or emotional bonds to their pet may be more likely to engage verbally or physically in incidents of family violence involving animals (Melson, 2003), potentially increasing their risk of physical injury and heightening risk for subsequent adjustment problems. Given empirical studies documenting that youth often turn to pets as confidantes (Katcher \& Beack, 1986, 1987), rely on animals as a way of managing stress (Melson, Schwartz, \& Beck, 1997), and list companion animals as important social relationships in their lives (Kosonen, 1996), we suggest that exposure to animal abuse may be particularly traumatic to children living in IPV-affected households (Melson, 2003; Yorke, 2010).

Current Study - In light of the reviewed literature, the experiences of children dually exposed to IPV and animal abuse warrant increased scholarly attention with specific 
consideration of how children living in these households experience threats and violence toward animals, how they are involved in incidents of companion animal-directed threats and harm, and the potential negative consequences to their physical and mental well-being. Building on Överlien and Hydén's (2009) recommendations, the current study seeks to better understand the issue of children exposed to IPV by adopting a qualitative childcentered approach that considers children as social agents and active participants in their ecological context, capable of serving as competent informants with stories that can expand empirical knowledge of the dynamics of family violence. Our research addresses and links two notable gaps in the literature: 1) the paucity of qualitative data reflecting children's lived experiences of violence in households affected by IPV and 2) interconnected and overlapping experiences of threats to and harm of companion animals among children living in IPV-affected households.

Our study was guided by two primary research questions: 1) What do children living in households affected by IPV recount of companion animals being threatened or harmed? and 2) What do children living in households affected by IPV describe about protecting companion animals who are threatened or harmed with violence?

\section{Method}

The data analyzed in this paper reflect baseline interviews with children collected as part of an ongoing longitudinal study on women and children's exposure to IPV and concomitant animal cruelty. Two hundred forty-two maternal caregiver-child dyads were recruited from 22 domestic violence (DV) agencies in the state of Colorado. The overall study employed a mixed-methods phenomenological research (MMPR) design using a concurrent model of data collection to guide descriptive inquiry (Giorgi, 2009; Mayoh \& Onwuegbuzie, 2015). Women were eligible to participate in the study if they: (a) reported experiencing IPV within the past year; (b) had at least one child between the ages of 7-12 in the home; and (c) reported the presence of at least one pet in the home within the past year. Following IRB approval, designated staff members from each DV agency were trained to recruit participants, obtain voluntary consent and assent, and administer surveys to eligible participants. This training also included coding instructions and safety strategies to protect participants' privacy and confidentiality.

Women who elected to participate in the study were asked to select one of their children between the ages of 7 and 12 to complete a series of structured and semi-structured questionnaires administered as an interview. Among the 242 children participating in the study, approximately $24 \%$ of the sample reported either a) experiencing someone threatening to harm or kill their pet and/or b) seeing or hearing someone hurt or kill their pet. The current qualitative study reflects interview data from this subset of children, who were asked a series of follow-up questions related to their exposure to animal-directed threats and/or harm.

\section{Child Interviews}

Due to the sensitive nature of the interview content, the assent procedures involved giving the child an opportunity to practice the right to break from or terminate the interview. In 
addition, survey administrators were instructed to complete the interview at the child's pace. The survey procedures were intentionally designed so that the last series of questions pertained to positive interactions with companion animals. In the event that a child was upset by the interview content, survey administrators were prepared to provide mothers with referrals for the child. However, none of the children who participated in the study required referrals as a result of the interview content or elected to terminate the interview. After completion of the interview, children were compensated $\$ 15$ for their time.

Interview Data-As previously addressed, the qualitative data analyzed in this paper reflect a portion of the overall interview schedule for the larger study. Specifically, responses to three questions from the Children's Observation and Experiences with Animals Survey (COEP; Ascione et al., 2007), which was administered as a semi-structured interview, were used in the current analysis. The COEP is a 15-item semi-structured questionnaire used to ask children about companion animal abuse experiences. The COEP has been used successfully in previous research with 5- to 17-year-old children. During this part of the interview, children were asked the following 3 questions: 1) Has anyone ever said they would hurt or kill one of your pets but not do it? 2) Have you ever seen or heard one of your pets hurt or killed? 3) Have you ever protected one of your pets or saved it from being hurt? When a child answered affirmatively, the interviewer prompted the child with the statement, "Please tell what happened as you remember it." Children were also prompted with "who-when-where-how-why" questions when responses necessitated clarification. In addition, children were asked to identify their relationship with the perpetrator of the reported threats or harm (e.g., friend, sibling, parent, stepparent). For the purposes of our study, the measure was also adapted in the Spanish language using the translation-backtranslation procedure (Van de Vijver \& Hambleton, 1996). Approximately 19\% of the interviews with children were conducted in Spanish and guided by an interviewer who was bilingual in Spanish and English.

All interviewers were instructed to record the exact words of the participants. Across participants, the average number of words of data generated for the three COEP questions was approximately 207. Due to the vulnerable state of the participants who were coping with traumatic events, audio and video data were not collected in order to maximize anonymity and confidentiality and minimize risks and additional stress. Moreover, audio/video recording was not logistically feasible in the larger study due to the number of data collection sites, potential burden on survey administrators, technical training requirements, and lack of secure storage space for equipment. Across interviews, children's responses were generally succinct and none of the survey administrators reported difficulty recording the exact words of the child participants. A professional translator provided English translations of the qualitative data from surveys completed in Spanish. 


\section{Sample Description 5}

The majority of children in the qualitative sample ( $\mathrm{N}=58)$ were female $(55 \%)$ with a mean age of 8.98 years $(S D=1.58)$. Mothers identified children racially or ethnically as follows: Native American or Alaska Native (1.7\%), African American or Black (1.7\%), White (36.2\%), Latino or Hispanic (31\%), and more than one race (29.3\%). The average yearly household income for this subsample of children was between $\$ 10,000$ and $\$ 20,000$, with $75.8 \%$ of the subsample reporting yearly household incomes under $\$ 30,000$ for the previous year. Approximately $83 \%$ of the sample lived in households with pet dogs and/or cats; other companion animals included birds, rabbits, and rodents.

\section{Analysis}

Using Atlas.ti 7.0 software (Atlas.ti Scientific Software Development, 2013), qualitative data were analyzed thematically using the method of template analysis (Crabtree \& Miller, 1999; King, 1998, 2012), an approach commonly employed to analyze large qualitative data sets in social science research (Brooks \& King, 2012). King and colleagues (King, 1998; Brooks \& King, 2012) note a synergy between template analysis and phenomenological approaches making it particularly well-suited for the overarching MMPR approach that guided the qualitative data collection. This method of analysis allows the researcher to match empirically observed data with a theoretically predicted template of a priori codes or to pursue open coding guided by a set of foci grounded in the research question(s) (King, 2012).

\section{Qualitative Analytic Steps}

Step 1-First, deductive methods were used to categorize data using a template of a priori codes developed by the first author. The a priori template consisted of codes specifically drawn from the COEP interview questions, which were refined and demarcated based on types of animal-directed threats and harm empirically documented in IPV-affected families (e.g., threats to harm animals as a power/control tactic) as well as strategies for coping with and responding to interparental violence among children (e.g., becoming verbally involved in interparental conflict). The first and fourth authors read initially through 10 transcripts and coded units of data that coincided with the a priori template. For example, for the code, "Threats of Animal Abuse as a Means of Power/Control by Mother's Partner", segments from interviews that were consistent with this type of violence exposure were coded as such, as exemplified by the following quote:

"My dad would say that he was going to burn him (cat) with a lighter if my mom left." -Boy, Age 8

Step 2-The next step of our analytic procedure involved further analysis of transcripts to identify experiences that were not captured by the initial template. The two authors coded 10 additional transcripts independently, and then met to compare codes. As a result of this meeting, codes were added, revised, or deleted. The template was revised to reflect

\footnotetext{
${ }^{5}$ Demographic information including yearly household income and child gender, age, and ethnicity were ascertained from a demographic survey completed by the mother.
} 
emerging patterns in the data accordingly. For example, we found a large number of data segments in which children reported on harm of pets by parents or siblings aimed to punish the animal for undesired behaviors. These quotes were assigned the code of "Animal Maltreatment as Punishment", such as the following text:

"My dad would hurt the dog because he would pee on the floor." - Boy, Age 11

This process of independent and concurrent coding was repeated until a final coding scheme, reflecting a priori and emergent codes, was developed. As data from each case were assigned codes, the parameters of each code were refined using strict guidelines and subsequent cases were coded appropriately. Some of the quotes represented concepts from more than one code; therefore, these segments were assigned multiple codes to reflect overlapping areas of the template.

Step 3-To examine the reliability of the data and findings, agreement among three raters was assessed. Data from eight cases were selected and the first, third, and fourth authors assigned codes to each data segment; raters were not forced to assign a specific number of cases to each category. Therefore, Randolph's free-marginal multirater kappa $\left(k_{\text {free }}\right.$; see Randolph, 2005, 2008; Warrens, 2010) was computed using Randolph's (2008) Online Kappa Calculator Computer Software. Values of multirater $k_{\text {free }}$ can range from -1.0 (perfect disagreement) to 1.0 (perfect agreement above chance). Free marginal kappa for the current analysis was .90 , indicating excellent inter-rater reliability. Once the initial inter-rater reliability was assessed, the first and fourth authors worked together to consider and resolve incidents of disagreement in the assignment of codes.

Step 4 \& 5-After applying the final coding template to all transcripts, we examined the data for saturation and the presence of each code across interviews to ensure that codes were common to multiple participants and not merely suggestive of outlier experiences (Strauss \& Corbin, 1998). Next, these codes were assessed for commonalities and classified into thematic groups based on common patterns. Specifically, grounded, inductive analysis was conducted to identify themes (Boyatzis, 1998; Glaser \& Strauss, 1967).

\section{Findings}

\section{Descriptive Information about Exposure to Animal Maltreatment}

As reported on the COEP, approximately $38 \%$ of children in the current study indicated that someone had hurt or killed their pet, $27 \%$ reported someone had threated to harm/kill their pet, and 35\% reported both threats to harm their pet and actual harm/killing of the animal. Nearly $78 \%$ of children who indicated exposure to threats or harm reported they had taken action to protect their pet.

\section{Qualitative Analysis}

Five core themes emerged from the qualitative analysis and are described in Table 1. 


\section{Research Question 1}

Our first research question pertained to what children recount about experiences of threats to and harm of companion animals in households affected by IPV. Three related themes were identified.

Theme 1-Power/Control in the Context IPV ( $n=29,50 \%$ of participants)

Children's experiences of threats to and harm of animals often resulted from actions taken by the mother's partner in the context of IPV. Specifically, children noted animal-directed threats and harm aimed to perpetuate fear in the home, isolate the mother, and prevent or punish the mother's efforts to leave or demonstrate independence. The following quotes 6 demonstrate children's experiences of animal-directed threats and harm as a tactic of power/ control by the abusive partner:

"The dog got hurt because dad kept kicking and kicking my dog. He didn't kill any pets until we got to shelter. When we went by there, my bird was gone." - Boy, Age 8

"My dad was very upset before Christmas with my mom because she had talked to her family in Mexico and was fighting with her when he said that he would burn my dog in our grill." - Girl, Age 11

"Cuando yo y mi mamá no limpiamos bien o nos levantamos temprano, él se enoja y empieza a patalear al perro con su bota y lo empieza aventar contra la pared una u otra vez." English Translation: "When my mom and I do not clean well or get up early, he (dad) gets angry and starts kicking the dog with his boot and starts throwing him against the wall time and time again." - Boy, Age 10

As demonstrated in last two quotes, children often described the abusive caregiver's negative emotions (e.g., anger) when describing their experience. Also, in several children's statements, animal maltreatment was described both as a tactic of power/control in the context of IPV and additionally as a behavior aimed to discipline/punish the pet, which emerged as a separate theme.

"My dad threatened to hurt them (pets), kill them, and get rid of them. Last time was two or three days before we came to shelter. My dad would hurt the dog because he would pee on the floor. Dog has been hurt when he is thrown down the stairs. My dad doesn't hurt him as much as he threatens to. He threatens Dog to [illegible] would him. He picks him up and throws him down the stairs. When Dog was 22 or 23 days old, my dad hit him across his snout - that started the getting hurt because Dog would pee." - Boy, Age 11

Theme 2-Punishment of Pets ( $n=14,24 \%$ of participants)

In response to being asked if they had ever seen someone hurt or kill their animal, children also frequently reported animal maltreatment by family members aimed to punish a pet for

\footnotetext{
${ }^{6}$ Identifying information such as names of pets and family members have been replaced. Clarifying information is provided in parentheses and brackets.
} 
undesirable behaviors. Threats of animal maltreatment related to punishing the animal were also prevalent. Interestingly, the actions children perceived as harm to the pet ranged widely in severity, from behaviors such as pulling too forcefully on a leash to throwing the pet so hard it lost consciousness. Unlike animal maltreatment as a tactic of IPV, children's experiences of harm to animals as punishment involved both mothers and partners. The breadth of experiences within this theme are demonstrated by the following quotes:

"My dad hurt my cat because she latched onto my leg and he tried to pull her off and then she latched onto him and he flung her into the cabinet and she passed out." -Girl, Age 8

"My mom said that she was going to hurt my dog. We were walking my dog and he was being bad. He kept pulling my mom with the leash so my mom said she was going to hurt him." -Girl, Age 9

"My dad kicked the dog when it tried to bite visitors to my house." -Girl, Age 7

"Cuando mi perro se sube a la cama o se sube al sofa mi papá lo empuja. Luego nos hace que lo saquemos del cuarto donde él esta. Mi papá no quiere que metan pelos." English Translation: "When my dog gets on the bed or on the couch my dad pushes him down. Then he makes us take the dog out of the room where he is. My dad doesn't like dog hair spreading all over the place." - Girl, Age 9

"My dog was having accidents. (Mother's partner said) 'I'm gonna kick this dogthis dog is going to be gone."”-Boy, Age 8

In addition to reports of caregivers' punishment of the animal, children also reported physical punishment of animals by siblings.

"My sister (name)-my cat was on her bed and she said, 'I'm gonna beat you!' He ran off. I was there watching that. He (the cat) ate our bird and we spanked him. Our sister spanked him. She just kind of went like this (demonstrated with her hand). That's the only time she ever hurt him."-Girl, Age 10

While animal maltreatment by siblings was prevalent in the context of punishment, children also reported threats to harm pets and animal maltreatment carried out by siblings outside the context of punitive behaviors. Thus, maltreatment carried out by siblings emerged as a separate theme.

Theme 3-Cruelty to Animals by Siblings ( $n=9,16 \%$ of participants)

Across participants, children disclosed exposure to siblings' abuse of pets in the home. Similar to the attributions children made for the motives of partner-perpetrated animal cruelty (e.g., anger), siblings' negative emotions were often described as the cause of their maltreatment of pets. For example, in one account of a sibling's reactive aggression, a child states:

"My little brother just got mad and threw the cat down the stairs." -Girl, Age 7

Other accounts of sibling-perpetrated animal maltreatment described deliberate cruelty that did not reflect emotional aggression. 
"Sometimes he (little brother) kicks him or teases him (dog)." -Boy, Age 7

"My brother sometimes tortures our cat. I used to, too. I used to torture my other cats. I don't now, but my brother still does." -Boy, Age 7

In incidents of more deliberate cruelty towards a pet, as exemplified in the previous quote, children frequently reported being in close proximity during their sibling's abuse of the pet and oftentimes described their own involvement in the maltreatment of the animal.

As previously mentioned, accounts of siblings' punishment of pets and siblings' nonpunishment motivated animal maltreatment often overlapped. However, these themes were clearly distinguishable, as illustrated by one child's response to being asked if someone had ever hurt or killed one of her pets:

"Only when the cat gets in trouble. She bites and scratches. I'd hear 'bad girl' and dad smacks her head like this. That's pretty normal cause that's what we do when the cat gets in trouble. For me, hurting her myself, it's 50 times, maybe more... cause everyone in my family has hurt the cat at least once. Because she would scratch and bite us for no reason. Sometimes, then, Dad and me and my sisters, basically my entire family, because she would bite us so we would scruff her-grab her by the back of her neck where there's extra neck skin. Sometimes older sister jostles her and throws her up. I tell her she's torturing her!" -Girl, Age 10

Four children, including this participant, described efforts to intervene in incidents of animal cruelty perpetrated by a sibling (i.e., "I tell her she's torturing [the cat]!"). The process of analyzing data regarding participants' efforts to protect pets was complicated by children's reports of their own ambiguous participation in their sibling's(s') acts of maltreatment. Due to this complexity, and the small number of children reporting strategies for protecting their pets from siblings, we were unable to examine themes in children's strategies for protecting pets from siblings separately from children's strategies for protecting pets from other household members when investigating our second research question.

Outliers: Eight children provided data that did not reflect any of the three themes. As descriptions of threats and harm among these children were not thematically related, these cases were considered outliers in the analysis. Multiple children $(n=4)$ reported on threats to animals that they wanted to have, but did not currently own. For example, when asked whether anyone had made threats to a pet in the home, one child stated, "I wanted to get rabbits but he said he would roast them..." While these cases provide interesting evidence of the use of threats against animals as a means of perpetuating fear in the household, they did not relate to threats against animals in the home, which was the focus of our analysis.

\section{Research Question 2}

Our second research question investigated when and how children protect companion animals who are threatened or harmed with violence in households experiencing IPV. Out of the 58 children reporting threats or harm to pets, $78 \%(n=45)$ also indicated they had protected a pet. In reference to this question, two additional themes emerged from the data: Preventative Protection and Direct Intervention. Notably, these themes did not overlap in the 
data; thus, children reporting preventative protection did not engage in direct intervention and vice versa. Furthermore, other than the few cases reporting efforts to protect a pet from a sibling, all examples of protection provided by children in our sample involved efforts to protect the pet from their mother's partner.

Theme 4-Preventative Protection from Mother's Partner ( $n=9 ; 16 \%$ of participants)

Several children in the sample reported actions aimed to prevent their mother's partner from harming companion animals. These preventative acts of protection occurred when there was no verbalized threat or in-progress harm to the animal by the mother's partner. Frequently, children reported relying on emotional or behavioral cues in order to determine when a pet needed to be removed from a potentially dangerous situation.

"When I see my dad is mad, I will take our bird out of the cage and put him in my room. Because I know he will pick the feathers out. When I see my dad mad, I will put the birds in a box under my bed so that if he throws the cage, they're not in there." -Boy, Age 9

"I would always hide my cat when my dad was drinking because I did not want him to hurt him. I would hide him in my closet with stuffed animals." -Boy, Age 8

In addition, children's strategies to prevent harm to their pet often involved relocating the pet to different locations in the house that were identified as "safe" to prevent interactions between their mother's partner and their pet.

"When I see my dad is getting mad, I take the dogs outside or in my room before he starts to kick them." - Girl, Age 9

"I make the cat stay downstairs so that my dad will not do nothing to him." -Boy, Age 10

"My dog always sleeps with me in my room so that my dad does not hurt him. My dad does not like the dog because my grandmother gave it to my mother." -Girl, Age 12

Theme 5-Direct Intervention Involving Mother's Partner ( $n=11,19 \%$ of participants)

When pets were threatened or harmed by the mother's partner, children frequently reported taking actions to intervene. Children's involvement in these incidents ranged in scope. Similar to the abovementioned strategies for preventing harm to pets when there was no immediate threat to the animal, in incidents of direct threats toward or harm of the pet, many children employed protective strategies aimed to reduce the proximity of the pet to the abusive partner.

"That day that my dad said he would burn my dog on the grill, I took him into my room and locked him in the closet with food and water until the next day." - Girl, Age 11

"Cuando mi papá trata de maltratar a mi perro yo lo protejo. Me lo llevo del cuarto y llevo a mi perro a donde el duerme para que mi papá no le pegue. Mi papá le 
pega con su gorra." English Translation: "When my dad tries to mistreat my dog, I protect him. I take my dog out of the room to the spot where he sleeps so that my dad would not kick him. My dad hits him with his hat." - Girl, Age 9

"When my dad is trying to get my dog, I get it and go outside with it so that he cannot hurt the dog." -Girl, Age 9

Other children reported more direct involvement with the mother's partner during incidents when a companion animal was harmed. This involvement was often characterized by both verbal and physical efforts to protect the animal.

"When my dad was trying to hurt my dog, I grabbed my dog and said, 'No, Dad, No.'" -Boy, Age 8

"I was trying to tell my dad not to tie my cat on the rope, but he did it anyways." Girl, Age 9

Outliers: It is important to note the relatively low percentage of children represented in Themes 4 and 5. Children's responses to being asked about their efforts to protect a pet frequently involved elaborate stories of imagined behaviors rather than accounts of past actions ( $\mathrm{n}=7$ ). In addition, 12 children in our study reported efforts to protect their pets that did not pertain to the animal being threatened with violence or harmed. The majority of these reports involved protecting the animal from going outside (i.e., "getting hit by a car"). Given that such responses did not relate to our research question, these cases were considered outliers.

\section{Discussion}

Our results, which emerged from child participants' responses to three questions from the COEP interview, explicate the manner in which children in households affected by IPV experience and intervene in threats to and harm of their companion animals. Our findings demonstrate that children's experiences are multifaceted, involving perceived maltreatment of pets at the hands of multiple family members. Children in our sample also recognized multiple motivations for animal maltreatment, such as negative emotions or discipline for undesirable animal behaviors. The data also reveal that children's involvement in these events involved both strategic efforts to preemptively prevent harm to companion animals, as well as reactive physical and verbal involvement in violent incidents. We also note that children report that they are sometimes directly involved as the abuser of their own pets. Our findings highlight the importance of qualitative research in this area of study and the ability of children's narratives to better illuminate the myriad experiences of violence in households impacted by IPV.

Elements of the themes that emerged from our data have been represented to some extent in previous empirical literature examining children's exposure to IPV and concomitant animal cruelty. With regard to Theme 1, children reported exposure to their mother's partner's threats to harm animals, animal maltreatment, and/or killing of pets. Our findings suggest that children are not only witness to these tactics, but they are able to identify threats to harm pets and/or acts of cruelty toward a pet as being intended to influence their maternal 
caregiver's behavior or to retaliate for acts of independence (e.g., leaving the home). These findings are consistent with previous reports indicating that women experience cruelty to pets as a tactic to exert power, control, and intimidation in the context of IPV (Arkow, 1996; Ascione, 1999; Ascione et al., 2007; Flynn, 2000; Millikin, 1999), particularly because IPV perpetrators disproportionately abuse pets with whom their partners identify a strong emotional attachment (Faver \& Cavazos, 2007; Onyskiw, 2007).

While mothers' behaviors were the primary target of their IPV perpetrating partners' coercive threats to or harm of animals, accounts within Theme 1 also speak to child-mother joint behaviors which were being retaliated against (e.g., "He didn't kill any pets until we got to shelter"; "Cuando yo y mi mamá no limpiamos bien o nos levantamos temprano..."). Children's reports of threats to and harm of animals as a tactic of coercion in response to their own actions may reflect a generalized use of coercive control by their mother's partners. Thus, animal-directed violence may function as a concurrent form of emotional abuse in the home when it is used by abusive partners to control, intimidate, and/or distress children (DeGue, 2011). For maternal caregivers who know that their child is being intimidated or controlled in this way, hearing or witnessing this coercion may exacerbate the already negative psychological and emotional consequences of living with IPV and lead to feelings of guilt, self-blame, and reduced confidence in their role as mother.

Children's exposure to harm of pets as a tactic of IPV overlapped with exposure to harm of pets as a form of animal punishment (Theme 2). Notably, animal maltreatment as pet punishment was engaged in by several members of the household, including mothers' partners, mothers, siblings, and the participants themselves. An abundance of literature has documented more frequent harsh physical punishment of children in households where there is IPV (Berger, 2005; Lee, Kotch, \& Cox, 2004; Tajima, 2000). Therefore, it is not surprising that physical disciplinary methods, which are prevalent in households impacted by IPV, would also be employed to punish companion animals. As suggested by DeGue (2011), it is also plausible that companion animals living in dysfunctional households may be more aggressive as a result of maltreatment, neglect, and training that reinforces aggressive behavior. In consequence, the aggressive behavior of the animal may contribute to the increased likelihood of other members of the family engaging in animal maltreatment with the goal of controlling or punishing the pet, thus promoting an environment that fosters cycles of multidirectional violence in the home involving companion animals (DeGue, 2011).

Findings emerging from our second theme also suggest that it may be important to distinguish the type of animal-directed threats and cruelty to which children are exposed when evaluating the impact of childhood animal cruelty exposure on subsequent interpersonal and animal-directed violence. Previous research on childhood animal cruelty exposure has failed to adequately attend to the motives which witnesses of animal cruelty attribute to the perpetrator's behavior. Our findings suggest that school-age children may prioritize motive over injury when making meaning of animal maltreatment (ex. "My dad hurt my cat because she latched onto my leg ... he flung her into the cabinet and she passed out") and/or that a normalization of injury may occur when justification is perceived. Such inferences may hold particular implications for children within this 7-12 age range as they 
grapple with the developmental tasks of refining consideration of motives and evaluating fairness.

Via social learning, children may act out observed punishment techniques on pets. While there is a dearth of literature on children's exposure to animal cruelty by siblings, which emerged as our third theme, our findings lend support to previous research demonstrating children exposed to IPV and/or animal cruelty are more likely to engage in maltreatment of animals (e.g., Felthous \& Kellert, 1986; Peterson \& Farrington, 2007; Tallichet \& Hensley, 2004). Exposure to sibling mistreatment of animals may be particularly multifaceted given evidence suggesting that sibling dynamics in the context of IPV-affected households are often marked by shifting alliances, competition, empathy deficits regarding sibling mistreatment, and collusion with abuse perpetrators (Bancroft, Silverman, \& Ritchie, 2011; Khan \& Rogers, 2015; Renner, 2012). Our findings also suggest that distinguishing between animal maltreatment aimed to punish the animal, versus cruelty aimed to "torture" the animal, is an important step in understanding children's exposure to siblings' animal cruelty as well as their own involvement in such incidents. A child's perceived distinction between disciplinary (i.e., justifiable) and retaliatory or aggressive (i.e., unacceptable or unnecessary) actions towards animals seems to influence their intervention decisions.

A child exposed to IPV's "appraisals of threat, coping efficacy, attributions about why violence occurs, and perceptions of justifiability of aggression" determine how a child understands their situation, and is believed to substantially influence immediate and longterm impacts of IPV exposure on child adjustment (Fosco, DeBoard, \& Grych, 2007, pg.10). Children's understanding of animal mistreatment and their decisions about whether and how to intervene may assist with identifying children at high risk for short-term as well as longterm negative impacts. Themes 4 and 5, which reveal the prompts for and methods of protecting companion animals, are also consistent with literature on children's involvement during IPV altercations. For example, Edleson and colleagues (2003) reported that among IPV-surviving women, a notable proportion of children verbally and/or physically intervened in incidents of IPV either "occasionally" or "very frequently"; moreover, the authors noted, "the greater the violence and its effects on their mothers, the more likely children are reported to intervene" (p.27). In regard to how children intervened on behalf of companion animals, participants described both preemptive protective measures and direct intervention including verbal and physical actions. Children's preemptive interventions demonstrate consideration and care for animal companions and highlight children's frequent use of increased geographic distance as a safety strategy. Knowing that children are more likely to intervene in more serious incidents of IPV, there are concerning implications for children who also intervene in incidents of animal cruelty given that the co-occurrence of IPV and animal abuse is primarily constrained to the highest severity situations (Ascione, 2007; DeGue, 2011: Simmons \& Lehman, 2007).

Our finding that children preemptively and directly intervene to protect companion animals from mistreatment suggests that pets are important to children, which is important to consider since within IPV affected households in particular, pets may be important resiliency agents providing comfort and consistency for children who are exposed to high levels of fear and uncertainty. In the context of IPV, parents may be less available for 
comforting children due to their parenting having been undermined by their abusive partner (Bancroft et al., 2011; Knickerbocker, Heyman, Smith-Slep, Jouriles, \& McDonald, 2007). In such environments, children may attach with non-parent others, including siblings (Renner, 2012), and may turn to animals for comfort and companionship (DeGue, 2011). As noted by Melson (2003), "children may cast their pets as functional younger siblings, as peer playmates, as their own 'children' or even as a security-providing attachment figure” (p. 37). Thus, the potential importance of a companion animal may be heightened for children experiencing IPV, and yet experiencing severe IPV also puts children at increased risk for being exposed to animal cruelty (Ascione et al., 2007; Volant et al., 2008). Within this duality, children experiencing IPV may be particularly likely to encounter "ambiguous loss" or "forced separation" from companion animals, and with potential heightened negative emotional impacts (Travis, 2014).

Based on self-report by child participants, this study invited the direct involvement of children who have been impacted by IPV to identify concerning situations involving their companion animals. Prior research regarding children's experiences of IPV has relied primarily on adult reports of child exposure; however, there is consensus among scholars that children are able to effectively articulate their experiences in the context of research interviews and serve as competent informants in qualitative research (Dockett \& Perry, 2007; Evang \& Överlien, 2014; Spratling, Coke, \& Minick, 2012). Our findings endorse children's capability as reporters of complex experiences involving family violence.

Children in this study provided information on a variety of actors and spoke not only about behaviors, but also about motivations for violence. Furthermore, children's reports of their own actions when faced with threats to or harm of companion animals underscores children as autonomous social agents with unique knowledge of their own participation in adverse settings.

\section{Limitations}

Findings of this study should be interpreted in light of several limitations. First, a more child-centered approach might have included opportunities for the child participants to review and provide input into tentative themes. Additionally, a stronger child-centered approach would expand on the method of interviewers' writing down children's responses to include a recorded interview in which children could more expansively describe their experiences for later transcription of their exact words and emotional content. It is possible that children's reports of threats to and/or harm of their companion animals may be underreported in our sample due to feelings of fear, guilt, or shame about such incidents and/or their response to such incidents. This may account for the relatively low number of children in the protection-related themes. Alternatively, had the COEP interview been characterized by greater precision of language pertaining to children's protection of animals when the animal was threatened or harmed with violence, this may have lead to more disclosures of children's protective efforts in the context of violent incidents. Further studies with more in-depth child-centered approaches are needed to assess this limitation. 


\section{Practice Implications}

Our findings have several implications for enhancing practice and interventions with caregivers and children experiencing complex trauma in households affected by IPV. First, it is important to note that most domestic violence agencies do not permit companion animals in shelter and there is a dearth of fostering services available to temporarily care for pets of survivors and their families. Intervention efforts should help children and women process potential feelings of guilt, helplessness, or responsibility for maltreatment experienced by a companion animal and/or having to relinquish a pet. In addition, given children's participation in incidents of family violence involving animals, intervention efforts should equip children with knowledge of how to protect their pets safely in order to decrease risk of physical injury and subsequent adjustment problems. Moreover, prior research suggests that children who are exposed to animal maltreatment are more likely to perpetrate animal cruelty in the future (Peterson \& Farrington, 2007; Tallichet \& Hensley, 2004). Caregivers should be educated on the potential impact that witnessing animaldirected violence may have on children and how to effectively model positive strategies for caring for and disciplining animals in the home. Hacket and Uprichard (2007) note that, "the presence of pets can represent a powerful opportunity to promote self-esteem, encourage the development of empathic concerns and encourage positive social interaction in children subject to psychosocial risk" (pg. 54). Humane education programs, which aim to foster positive relationships with animals, may have important implications for children exposed to IPV and concomitant animal cruelty.

A growing number of states have enacted legislation mandating cross-reporting among child protection and animal welfare agencies (DeGue \& DiLillo, 2009). Nonetheless, many professions have a piecemeal approach to identifying and reporting animal abuse. Additional cross-system education and coordination including child welfare departments, veterinary professionals, law enforcement, and animal control would facilitate prompt and integrated responses which stand to benefit child and adult safety as well as that of animals. To facilitate community-wide cross-reporting, Long and Kulkarni, (2013) endorse interorganizational capacity building via cross-systems training, creation of standards, and adoption of new administrative practices. Furthermore, all such multi-disciplinary initiatives should explore ways to enhance adult domestic violence survivors' resources for safety planning, which is a dynamic and complex process (Davies \& Lyon, 2013).

\section{Future Directions for Research}

Given the overlap of themes across participants, our findings support the assertion made by DeGeu and DiLillo (2009) that "some families may be prone to generalized physical violence, with lines blurred between victims and perpetrators" (p.1052). It is reasonable to assume that there are variances in both exposure patterns and cognitive appraisals, which lead children to respond differentially to acute violence. Additional research is needed to explore how children exposed to IPV understand the antecedents, motives, and consequences of violence towards companion animals, and how those assessments influence children's feelings of blame, guilt, and decisions about responding to threats of or use of violence against a pet. Such information may clarify situations in which children are most at risk due to physically intervening in an adult offender's violent act. Furthermore, such 
information can help parse out distinctions in children's meaning making of animal maltreatment in the context of IPV and illuminate the mechanisms by which their perceptions may influence long-term maladjustment. We also recommend that future research explore how children cope with violence toward their companion animals beyond actions to protect their pet and investigate how the well-being of children in residential IPV services is influenced by children's concerns for pets that are unable to accompany the family to shelter.

\section{Acknowledgements}

This research was funded by Grant 5R01-HD-66503-4 from the Eunice Kennedy Shriver National Institute of Child Health and Human Development (NICHD) and Grant 2015-0709 from the American Society for the Prevention of Cruelty to Animals (ASPCA). The content is solely the responsibility of the authors and does not necessarily represent the official views of the National Institutes of Health or ASPCA. This paper was presented in part at the Annual Meeting of the Society for Social Work and Research in January 2015 in New Orleans, LA. The authors would like to thank the community-based domestic violence advocates for their contribution to this work.

\section{References}

Adamson JL, Thompson RA. Coping with interparental verbal conflict by children exposed to spouse abuse and children from nonviolent homes. Journal of Family Violence. 1998; 13(3):213-232.

Arkow P. The relationships between animal abuse and other forms of family violence. Family Violence and Sexual Assault Bulletin. 1996; 12(1-2):29-34.

Ascione, FR. The abuse of animals and human interpersonal violence: Making the connection. In: Ascione, FR.; Arkow, P., editors. Child abuse, domestic violence, and animal abuse: Linking the circles of compassion for prevention and intervention. Purdue University Press; West Lafayette, IN: 1999. p. 50-61.

Ascione, FR. Emerging research on animal abuse as a risk factor for intimate partner violence. In: Kendall-Tackett, K.; Giacomoni, S., editors. Intimate partner violence. Civic Research Institute; Kingston, NJ: 2007. p. 3.1-3.17.

Ascione, FR. Examining children's exposure to violence in the context of animal abuse. In: Linzey, A., editor. The link between animal abuse and human violence. Sussex Academic Press; Portland, OR: 2009. p. 106-115.

Ascione FR, Weber CV, Thompson T, Heath J, Maruyama M, Hayashi K. Battered pets and domestic violence: Animal abuse reported by women experiencing intimate violence and by non-abused women. Violence Against Women. 2007; 13(4):354-373. [PubMed: 17420515]

Atlas.ti Scientific Software Development. ATLAS.ti Version 7.0 [Computer software]. Berlin, Germany: 2013.

Bancroft, L.; Silverman, JG.; Ritchie, D. The batterer as parent: Addressing the impact of domestic violence on family dynamics. Sage Publications; Thousand Oaks, CA: 2011.

Berger LM. Income, family characteristics, and physical violence toward children. Child Abuse \& Neglect. 2005; 29(2):107-133. [PubMed: 15734178]

Boat, BW. Abuse of children and abuse of animals: Using the links to inform child assessment and protection. In: Ascione, FR.; Arkow, P., editors. Child abuse, domestic violence, and animal abuse. Purdue University Press; West Lafayette, IN: 1999. p. 83-100.

Boyatzis, RE. Transforming qualitative information: Thematic analysis and code development. Sage Publications, Inc.; Thousand Oaks, CA: 1998.

Brooks, J.; King, N. Qualitative psychology in the real world: The utility of template analysis. Paper presented at the 2012 British Psychological Society Annual Conference; London, UK. Apr. 2012 Retrieved from: http://eprints.hud.ac.uk/13656/1/BrooksKing_QMiP_2012_Final.pdf

Carlson BE. Children exposed to intimate partner violence research findings and implications for intervention. Trauma, Violence, \& Abuse. 2000; 1(4):321-342. 
Crabtree BF, Miller WL. Using codes and code manuals: A template organizing style of interpretation. Doing Qualitative Research. 1999; 2:163-177.

Cunningham, A.; Baker, L. What about me! Seeking to understand the child's view of violence in the family. Centre for Children and Families in the Justice System; London, Ontario: 2004.

Currie CL. Animal cruelty by children exposed to domestic violence. Child Abuse and Neglect. 2006; 30:425-435. [PubMed: 16600374]

Davies, J.; Lyon, E. Domestic violence advocacy: Complex lives/difficult choices. Sage Publications; Thousand Oaks, CA: 2013.

DeGue, S. A triad of family violence: Examining overlap in the abuse of children, partners, and pets. In: Blazina, C.; Boyra, G.; Shen-Miller, DS., editors. The psychology of the human-animal bond. Springer-Verlag; New York, NY: 2011. p. 245-262.

DeGue S, DiLillo D. Is animal cruelty a "red flag" for family violence? Investigating co-occurring violence toward children, partners, and pets. Journal of Interpersonal Violence. 2009; 24(6):10361056. [PubMed: 18544751]

Dockett S, Perry B. Trusting children's accounts in research. Journal of Early Childhood Research. 2007; 5(1):47-63.

Edleson JL, Ellerton AL, Seagren EA, Kirchberg SL, Schmidt SO, Ambrose AT. Assessing child exposure to adult domestic violence. Children and Youth Services Review. 2007; 29(7):961-971.

Edleson JL, Shin N, Armendariz KKJ. Measuring children's exposure to domestic violence: The development and testing of the Child Exposure to Domestic Violence (CEDV) Scale. Children and Youth Services Review. 2008; 30:502-521.

Evang A, Överlien C. 'If you look, you have to leave': Young children regulating research interviews about experiences of domestic violence. Journal of Early Childhood Research. 2014 Advance Online Publication. doi: 10.1177/1476718X14538595.

Faver CA, Cavazos AM. Animal abuse and domestic violence: A view from the border. Journal of Emotional Abuse. 2007; 7(3):59-81.

Faver CA, Strand EB. To leave or to stay? Battered women's concern for vulnerable pets. Journal of Interpersonal Violence. 2003; 18(12):1367-137. [PubMed: 14678611]

Faver CA, Strand EB. Fear, guilt, and grief: Harm to pets and the emotional abuse of women. Journal of Emotional Abuse. 2007; 7(1):51-70.

Felthous AR, Kellert SR. Violence against animals and people: Is aggression against living creatures generalized? Journal of the American Academy of Psychiatry and the Law Online. 1986; 14(1): 55-69.

Finkelhor D, Ormrod RK, Turner HA, Avery-Leaf S, Cascardi M, O'Leary KD, Cuevas C. Polyvictimization and trauma in a national longitudinal cohort. Development and Psychopathology. 2007; 19(1):149. [PubMed: 17241488]

Finkelhor D, Turner H, Ormrod R, Hamby SL. Violence, abuse, and crime exposure in a national sample of children and youth. Pediatrics. 2009; 124(5):1411-1423. [PubMed: 19805459]

Flynn CP. Woman's best friend: Pet abuse and the role of companion animals in the lives of battered women. Violence Against Women. 2000; 6(2):162-177.

Flynn CP. Why family professionals can no longer ignore violence toward animals. Family Relations. 2000b; 49(1):87-95.

Flynn, C. Women-battering, pet abuse, and human-animal relationships. In: Linzey, A., editor. The link between animal abuse and human violence. Sussex Academic Press; Portland, OR: 2009. p. 116-125.

Flynn CP. Examining the links between animal abuse and human violence. Crime, Law and Social Change. 2011; 55(5):453-468.

Fosco GM, DeBoard RL, Grych JH. Making sense of family violence: Implications of children's appraisals of interparental aggression for their short-and long-term functioning. European Psychologist. 2007; 12(1):6-16.

Giori, A. The descriptive phenomenological method in psychology. Duquesne University Press; Pittsburgh, PA: 2009. 
Glaser, B.; Strauss, A. The discovery grounded theory: Strategies for qualitative inquiry. Wiedenfeld and Nicholson; London, England: 1967.

Hackett, S.; Uprichard, E. Animal abuse and child maltreatment: A review of the literature and findings from a UK study. NSPCC; London: 2007.

Hamby, SL.; Finkelhor, D.; Turner, HA.; Ormrod, R. Juvenile Justice Bulletin. U.S. Government Printing Office; Washington, DC: 2011. Children's exposure to intimate partner violence and other family violence; p. 1-12.

Hester, M.; Kelly, L.; Radford, J., editors. Open University Press; Bristol, PA: 1996. Women, violence, and male power: Feminist activism, research, and practice; p. 81-98.

Jaffe PG, Hurley DJ, Wolfe D. Children's observations of violence: I. Critical issues in child development and intervention planning. The Canadian Journal of Psychiatry. 1990; 35(6):466470.

Joseph S, Govender K, Bhagwanjee A. "I can't see him hit her again, I just want to run away... hide and block my ears". A phenomenological analysis of a sample of children's coping responses to exposure to domestic violence. Journal of Emotional Abuse. 2006; 6(4):23-45.

Katcher AH, Beck AM. Dialogue with animals. Transactions \& Studies of the College of Physicians of Philadelphia. 1986; 8(2):105-112. [PubMed: 3727005]

Katcher A, Beck A. Health and caring for living things. Anthrozoös. 1987; 1(3):175-183.

Khan R, Rogers P. The normalization of sibling violence: Does gender and personal experience of violence influence perceptions of physical assault against siblings? Journal of Interpersonal Violence. 2015; 30(3):437-458. [PubMed: 24919998]

King, N. Template analysis. In: Cassell, CM.; Symon, G., editors. Qualitative methods in organizational research: A practical guide. Sage Publications, Inc.; London: 1998. p. 118-34.

King, N. Doing template analysis. In: Symon, G.; Cassell, C., editors. Qualitative organizational research. Sage Publications, Inc.; Thousand Oaks, CA: 2012. p. 426-50.

Knickerbocker L, Heyman RE, Smith Slep AM, Jouriles EN, McDonald R. Co-occurrence of child and partner maltreatment. European Psychologist. 2007; 12(1):36-44.

Kosonen M. Siblings as providers of support and care during middle childhood: Children's perceptions. Children \& Society. 1996; 10(4):267-279.

Lee LC, Kotch JB, Cox CE. Child maltreatment in families experiencing domestic violence. Violence and Victims. 2004; 19(5):573-591. [PubMed: 15844726]

Long DD, Kulkarni SJ. Cross-reporting of interpersonal violence and animal cruelty: The Charlotte Project. Journal of Sociology and Social Welfare. 2013; 40(4):131-148.

Petersen M, Farrington DP. Cruelty to animals and violence to people. Victims and Offenders. 2007; 2(1):21-43.

Lynch M, Cicchetti D. An ecological-transactional analysis of children and contexts: The longitudinal interplay among child maltreatment, community violence, and children's symptomatology. Development and Psychopathology. 1998; 10(02):235-257. [PubMed: 9635223]

Margolin, G. Effects of domestic violence on children. In: Trickett, PK.; Schellenbach, CJ., editors. Violence against children in the family and the community. American Psychological Association; Washington DC: 1998. p. 57-102.

Margolin G, Vickerman KA, Ramos MC, Serrano SD, Gordis EB, Iturralde E, Oliver PH, Spies LA. Youth exposed to violence: Stability, co-occurrence, and context. Clinical Child and Family Psychology Review. 2009; 12(1):39-54. doi:10.1007/s10567-009-0040-9. [PubMed: 19238543]

McCabe KM, Hough RL, Yeh M, Lucchini SE, Hazen A. The relation between violence exposure and conduct problems among adolescents: A prospective study. American Journal of Orthopsychiatry. 2005; 75(4):575-584. [PubMed: 16262515]

McGee, C. Childhood experiences of domestic violence. Jessica Kingsley Publishers; London: 2000.

Melson GF. Child development and the human-companion animal bond. American Behavioral Scientist. 2003; 47:31-39.

Melson GF, Schwarz RL, Beck AM. Importance of companion animals in children's livesimplications for veterinary practice. Journal of the American Veterinary Medical Association. 1997; 211(12):1512-1518. [PubMed: 9412676] 
Millikin, M. First-person account: Life and death inside the cycles of violence. In: Ascione, FR.; Arkow, P., editors. Child abuse, domestic violence, and animal abuse: Linking the circles of compassion for prevention and intervention. Purdue University Press; West Lafayette, IN: 1999. p. 176-188.

Mayoh J, Onwuegbuzie AJ. Toward a Conceptualization of Mixed Methods Phenomenological Research. Journal of Mixed Methods Research. 2015; 9(1):91-107.

Onyskiw JE. The link between family violence and cruelty to family pets. Journal of Emotional Abuse. 2007; 7(3):7-30.

Överlien C, Hydén M. Children's actions when experiencing domestic violence. Childhood. 2009; 16(4):479-496.

Randolph, J. Multi-rater, free-marginal variation of the Fleiss Kappa: An alternative to Fleiss' fixedmarginal multi-rater kappa. Paper presented at the 2005 Joensuu University Learning and Instruction Symposium; Joensuu, Finland. Oct. 2005 Retrieved from http:/www.researchgate.net/ profile/Justus_Randolph/publication/224890485_Freemarginal_multirater_kappa_An_alternative_to_Fleiss'_fixed-marginal_multirater_kappa/links/ 54499bcc0cf2ea6541341575.pdf

Randolph, J. Online Kappa Calculator. 2008. Retrieved January 5, 2015. http://justusrandolph.net/ kappa/

Renner LM. Intrafamilial physical victimization and externalizing behavior problems: Who remain the 'forgotten' children? Aggression \& Violent Behavior. 2012; 17(2):158-170.

Scott KL, Crooks CV. Effecting change in maltreating fathers: Critical principles for intervention planning. Clinical Psychology: Science and Practice. 2004; 11(1):95-111.

Simmons CA, Lehmann PL. Exploring the link between pet abuse and controlling behaviors in violent relationships. Journal of Interpersonal Violence. 2007; 22:1211-1222. [PubMed: 17704464]

Solberg A. How do children relate to violence in the home? Norges Barnevern. 2004; 3:3-9.

Spratling R, Coke S, Minick P. Qualitative data collection with children. Applied Nursing Research. 2012; 25(1):47-53. [PubMed: 20974094]

Strauss, A.; Corbin, J. Basics of qualitative research: Grounded theory procedures and techniques. Sage; Newbury Park, CA: 1990.

Tajima EA. The relative importance of wife abuse as a risk factor for violence against children. Child Abuse \& Neglect. 2000; 24(11):1383-1398. [PubMed: 11128172]

Tallichet SE, Hensley C. Exploring the link between recurrent acts of childhood and adolescent animal cruelty and subsequent violent crime. Criminal Justice Review. 2004; 29(2):304-316.

Thompson KL, Gullone E. An investigation into the association between the witnessing of animal abuse and adolescents' behavior toward animals. Society \& Animals. 2006; 14(3):221-243.

Travis, HJ. Children and the human-animal bond: Minimizing pet loss during disasters. In: Jalongo, MR., editor. Teaching Compassion: Humane Education in Early Childhood. Springer; New York, NY: 2014. p. 133-145.

Van de Vijver F, Hambleton RK. Translating tests: Some practical guidelines. European Psychologist. 1996; 1(2):89-99.

Volant AM, Johnson JA, Gullone E, Coleman GJ. The relationship between domestic violence and animal abuse: An Australian study. Journal of Interpersonal Violence. 2008; 23:1277-1295. [PubMed: 18326483]

Warrens MJ. Inequalities between kappa and kappa-like statistics for $\mathrm{k} \times \mathrm{k}$ tables. Psychometrika. 2010; 75:176-185.

Yorke J. The significance of human-animal relationships as modulators of trauma effects in children: A developmental neurobiological perspective. Early Child Development and Care. 2010; 180(5): 559-570. 


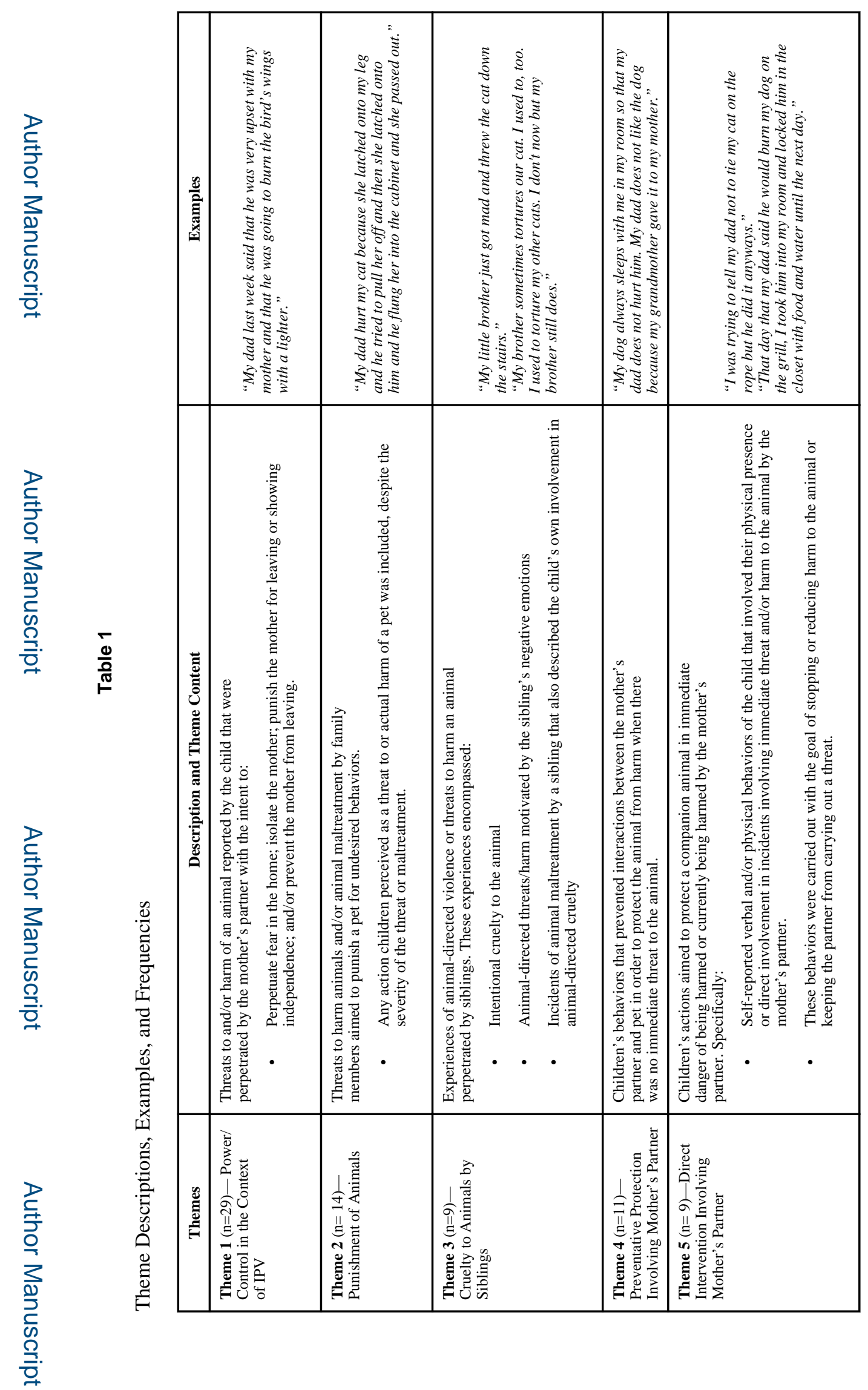

Child Abuse Negl. Author manuscript; available in PMC 2016 December 01. 